\title{
ELOGIO A LA CONCORDIA Y LLAMADA A LA REFORMA DE NUESTRA CONSTITUCIÓN ${ }^{1}$
}

\author{
ÁLVARO RODRÍGUEZ BEREIJO \\ Ex Presidente del Tribunal Constitucional
}

Ante todo quiero agradecer a la Fundación Fernando Abril y a su Junta Directiva el gran honor que me dispensan al ofrecerme pronunciar ante Vds. el «elogio de la concordia».

Iustitia, Libertas, Concordia es el lema que figura en la medalla que lleva en su pecho cada Magistrado del Tribunal Constitucional y que yo también llevé, sintiéndolo como propio aún después de haber cesado en esa responsabilidad, porque es bien expresiva de los valores primordiales que deben guiarnos en una sociedad política democrática y plural ordenada por el Derecho.

He de confesar que «carezco de esa facilidad que veo en otros para entretener al auditorio sin cansar los oídos», como decía Montaigne, así que procuraré ser muy breve en mi intervención.

Vivimos, España vive, tiempos azarosos. Los valores que guiaron los primeros pasos de nuestra Transición política y los de nuestra Democracia — la voluntad de concordia, la tolerancia y la convivencia en libertad y pluralismo- parecen perder presencia en una sociedad cada vez más crispada por las consecuencias, de todo orden, de la crisis económica y el comportamiento de nuestros dirigentes políticos.

Pero este hecho, por persistente que parezca, no resta, no debería restarle, un ápice a su vigencia como valores permanentes que deben ordenar nuestra convivencia política.

La circunstancia que nos convoca aquí esta noche, el otorgamiento del Premio Fernando Abril Martorell, que tanto luchó por enraizarlos en nuestra arquitectura política, es un buen testimonio de ello.

Antonio Muñoz Molina encarna admirablemente, como escritor y como hombre, el compromiso cívico con los valores más puros de la democracia: la libertad, la dignidad y el respeto a los derechos de la persona en una sociedad más igualitaria y más justa; en las antípodas de las simplificaciones de la Historia, de los partidismos y de las banderías a las que somos tan proclives.

1 Discurso en la entrega del Premio Fernando Abril Martorell a Antonio Muñoz Molina en Madrid el 7 de junio de 2011. 
«He aprendido a convivir con la inseguridad y con el desaliento, con la incertidumbre irremediable sobre el valor de lo que he hecho, con la vulnerabilidad ante los juicios negativos y la sospecha de que puedan ser menos infundados que algunos elogios», escribió de sí mismo muy recientemente.

«Hay muchas cosas que me gustan de España y otras que me inquietan, que me dan miedo, que me hacen sentirme vulnerable y forastero: la facilidad para el insulto, sobre todo, la violencia verbal gratuita e incontrolada, la disposición a no conceder crédito ni tregua ni respeto a quien tiene una opinión distinta o no secunde ciertas modas obligatorias. No me gusta que no haya límites de decoro ni de formalidad ni de buena educación», dijo en cierta ocasión.

Cada uno bien podría poner cara, ojos y boca a estas palabras suyas nobles, certeras, que ilustran perfectamente los valores de tolerancia y humanismo que animan a Antonio Muñoz Molina como persona y como escritor y hacen tan oportuno el premio con el cual, merecidamente, la Fundación Abril Martorell ha querido distinguirlo.

Tengo para mí que nuestra Transición política no se debió, como algunos dicen, a la amnesia u olvido de las páginas más negras de nuestro pasado más reciente; antes al contrario siempre he creído que fue el resultado perfectamente consciente y querido de un ejercicio de memoria histórica, de una Historia que no queremos que vuelva a repetirse en España. Y lo tengo para mí, aunque sólo sea por aquello de que «el pueblo que ignora su propia Historia está condenado a repetirla».

El espíritu de concordia política y, por qué no decirlo, de generosidad que en nuestra Transición llevó a cesiones en sus idearios políticos por parte de todos y no sólo, ni siquiera principalmente, por parte de los partidos nacionalistas, tuvo su fruto más granado en nuestra Constitución, "la Constitución de la concordia», elaborada desde el consenso y no, como otras de nuestro pasado histórico, hecha por una mitad de los españoles para ser impuesta a la otra mitad. Y es mucho lo que los españoles debemos a la función pacificadora de nuestra Constitución.

En una sociedad democrática, libre y plural, la «concordia» supone la convivencia en una diversidad ordenada jurídicamente, es decir regida por el Derecho. La «concordia» tiene mucho que ver con la «tolerancia», aunque sean conceptos en sí mismos distintos. Concordar es la voluntad de poner en común normas, ideas o proyectos, lo que requiere mutua tolerancia respecto del punto de vista del otro. Pero en un Estado de Derecho en el que están reconocidos y garantizados los derechos fundamentales y las libertades públicas «la tolerancia», como virtud social, cívica, no es un bien absoluto y encuentra límites: el límite del respeto a los derechos y libertades garantizadas en la Constitución.

No hay, no debe haber, tolerancia con quienes no respetan el derecho o la libertad de los demás. Más aún, el respeto debido a la Constitución y a los derechos consagrados en ella nos demanda intolerancia frente a los intolerantes, frente a quienes vulneran las leyes o no respetan los derechos reconocidos o atentan contra la libertad de todos. Así pues, «concordia» como virtud cívica sí. Pero no cabe «concordar» con todos ni con todo, ni, por tanto, con cualquier idea o proyecto político o social. El límite de «la concordia» debe estar en los valores, principios y derechos que se proclaman en la Constitución que el pueblo se ha dado a sí mismo y en el respeto a las leyes que emanan de ella.

Y si el devenir nos muestra que aquellos valores y principios en que ésta se sustenta han cambiado y no es posible ya renovar el consenso en torno a ellos, será necesario 
afrontar con serenidad y firmeza una reforma de la Constitución misma. Pero nunca «concordar» algo al margen o por encima de ella, sacrificando sus valores más esenciales.

La tarea más difícil que nos incumbe como ciudadanos es, a mi modo de ver y aún a riesgo de parecer cursi, el «patriotismo constitucional» renovando, como si de un plebiscito cotidiano se tratase, aquello que de permanente tiene nuestra Constitución: sus valores y principios. Venciendo la desgana y aún la molicie que parece atenazarnos en esta España de comienzos del nuevo siglo, donde la Política, como espacio común en el que se gestionan los asuntos públicos, parece haberse reducido al estrecho y mezquino ámbito en el que se mueven los profesionales de la política y de la opinión publicada.

Y es cada día más necesario ese despertar cívico a fin de evitar que la desgana, la indiferencia o el desencanto que a veces nos invade acabe por imponer su designio, el pesimismo de la razón, al que ha de oponerse, como pedía Gramsci, el optimismo de la voluntad. Optimismo que bien puede encontrar un firme asidero en los valores de «concordia» y convivencia en paz, pluralismo y libertad que en su día alentaron también a los españoles en nuestra Transición democrática.

Es cierto que vivimos tiempos en los que incertidumbres tanto económicas como políticas arrojan no pocas sombras sobre nuestra evolución futura. Precisamente por ello reafirmar los valores que animaron a nuestra Constitución y a nuestra Democracia es importante y, en cierto modo, continúan siendo una apuesta cívica y moral para cada uno de nosotros. Tanto más cuando se demanda, no sin razón, una reflexión crítica sobre el camino recorrido y las consecuencias políticas y prácticas que resultan de la complejidad de las fórmulas y técnicas utilizadas para la organización política y territorial del Estado. En la consciencia de que el problema es cómo articular mecanismos que permitan poner el acento en la unidad y la solidaridad, principios sobre los que se asienta el modelo de autonomía territorial querido por la Constitución. Tener en cuenta «el todo por encima de las partes».

Porque hoy el verdadero desafío es cómo prevenir los riesgos de la fragmentación política y cómo restaurar la confianza en las instituciones basilares de nuestro Estado constitucional trabajosamente construido a lo largo de estos años.

Lord Macaulay, con ocasión de la aprobación del Acta de Reforma de 1832, dijo ante la Cámara de los Comunes que «la gran causa de las revoluciones es que mientras las naciones se mueven hacia adelante, las Constituciones permanecen inmóviles».

Tal vez sea necesario que nos movamos y hacer balance de la experiencia democrática y constitucional más larga y fructífera de la Historia de España respecto de nuestra compleja estructura política del Estado, de su entramado institucional así como de su adecuación para hacer frente a los desafíos que comporta un entorno mundial cada vez más integrado y competitivo y sobre todo, respecto de su sostenibilidad tanto política como financiera. Pero teniendo muy presentes, también, los riesgos. Y éstos los expresó muy bien, ya en 1994, Francisco Tomás y Valiente, sólo dos años antes de ser vilmente asesinado por ETA en su despacho de la Universidad Autónoma de Madrid, con una clarividencia que ha resultado premonitoria:

«Si se cuestionan las decisiones políticas fundamentales sintetizadas en el Art. 2 de la Constitución; si los líderes políticos prefieren el ruido de las declaraciones estridentes al sonido de la palabra racional y razonable; si no se esfuerzan por poner fin al proceso constituyente de este Estado peligrosamente abierto y optan por desorientar al ciudadano con ofertas unilaterales; si todo esto continúa sucediendo, podría generalizarse e im- 
ponerse su vaticinio: la lúcida tentación del pesimismo. Contra ella debería prevalecer la confianza democrática y la activa voluntad de acuerdo y de convivencia dentro de esta Constitución y estos Estatutos por parte de los principales dirigentes políticos».

$* * *$

Title: In Praise of Concord and Pray for Constitutional Reform in Spain

ABSTRACT: This paper contains the speech of Álvaro Rodríguez Bereijo, Ex-president of the Spanish Constitutional Court, pronounced in the presentation of the Fernando Abril Martorell Award 2011, and it focuses on reminding the spirit of concord in the elaboration process of the Spanish Constitution of 1978 and on encouraging to face the reform of this Constitution with the same spirit of concord and looking for the same consensus as in 1978.

ReSumen: En esta publicación se recoge el discurso del Álvaro Rodríguez Bereijo, ex Presidente del Tribunal Constitucional español, pronunciado en la entrega del Premio Fernando Abril Martorell 2011, y que se centró en recordar el espíritu de concordia y el consenso que presidió la elaboración de la Constitución de 1978 y en animar a encarar la reforma de la misma con ese mismo espíritu de concordia.

KeY Words: Constitution. Reform. Concord. Consensus.

Palabras Clave: Constitución. Reforma. Concordia. Consenso.

FECHA DE RECEPCIÓN: 06.02.2012 FECHA DE ACEPTACIÓN: 15.02.2012 